\title{
The Effect of the Postdivorce Relationship on Paternal Involvement: A Longitudinal Analysis
}

\author{
Constance R. Ahrons \\ University of Southern California
}

Richard B. Miller

Brigham Young University - Provo, rick_miller@byu.edu

Follow this and additional works at: https://scholarsarchive.byu.edu/facpub

Part of the Family, Life Course, and Society Commons

\section{Original Publication Citation}

Ahrons, C.R. and Miller, R.B. (1993), The Effect of the Postdivorce Relationship on Paternall Involvement: A Longitudinal Analysis. American Journal of Orthopsychiatry, 63: 441-450.

\section{BYU ScholarsArchive Citation}

Ahrons, Constance R. and Miller, Richard B., "The Effect of the Postdivorce Relationship on Paternal Involvement: A Longitudinal Analysis" (1993). Faculty Publications. 3977.

https://scholarsarchive.byu.edu/facpub/3977 


\title{
THE EFFECT OF THE POSTDIVORCE RELATIONSHIP ON PATERNAL INVOLVEMENT: A Longitudinal Analysis
}

\author{
Constance R. Ahrons, Ph.D., and Richard B. Miller, Ph.D.
}

Longitudinal analyses of data from 64 pairs of former spouses indicate that the quality of their postdivorce relationship had a significant impact on fathers' involvement with their children. The strength of the influence declined over time, however, as the patterns of interaction in the reorganized binuclear family became more stable.

$\mathrm{W}$ ith the prevalence of divorce in American society, the attention of researchers, clinicians, and policy makers has focused on ways to decrease the negative impact of divorce on children. Although the divorce rate stabilized during the $1980 \mathrm{~s}$, an estimated $40 \%$ to $50 \%$ of children born in the United States during the late 1970s and early 1980s will experience the divorce of their parents (Ahlburg \& De Vita, 1992; Glick, 1990).

Research has indicated that divorce can be an extremely stressful transition for many children (Guidubaldi, Cleminshaw, Perry, \& McLoughlin, 1983; Guidubaldi \& Perry, 1984, 1985; Hetherington \& Camara, 1984; Hetherington, Cox, \& Cox, 1982; Peterson \& Zill, 1986; Wallerstein, 1991; Zill, 1983). Although most children eventually adjust to their parents' divorce, a substantial minority suffer negative long-term effects (Hetherington, Cox, \& Cox, 1985; Hetherington, Stanley-Hagan, \& Anderson, 1989; Wallerstein, 1985; Wallerstein \& Kelly, 1980).

The research findings are contradictory and inconclusive about which predivorce and postdivorce factors mediate the negative effects of divorce on children. However, the continuing involvement of divorced fathers in families where mothers maintain physical custody has become recognized as an important mediating factor in the adjustment and well-being of children of divorce (Hess \& Camara, 1979; Hetherington \& Camara, 1984; Hetherington et al., 1989; Isaacs, 1988; Jacobson, 1978; Kelly, 1993; Peterson \& Zill, 1986; Tschann, Johnston, Kline, \& Wallerstein, 1989; Wallerstein \& Kelly, 1980). Hetherington et al. (1982) concluded that, unless the father is poorly adjusted or immature, or there is a lot of conflict between the parents, frequent contact with the father is associated with positive adjustment of the children.

Why fathers do or do not stay involved with their children following divorce is another complex issue with many possible mediating factors. Several studies have suggested that the quality of the relationship

A revised version of a paper submitted to the Journal in February 1992. Authors are at: Department of Sociology, University of Southern California, Los Angeles (Ahrons); and Department of Human Development and Family Studies, Kansas State University, Manhattan (Miller). 
between the former spouses is an important predictor of paternal involvement. Guidubaldi and Perry (1985) reported that the association between the amount of fatherchild contact and the children's positive adjustment was especially true when the mother approved of the continuing relationship between the father and his children. Koch and Lowery (1985) found that $36 \%$ of the variance in noncustodial fathers' visiting patterns was explained by the quality of the former spousal relationship. Tepp (1983) reported that the quality of the coparental relationship had a strong correlation with the father's involvement in child rearing, but only a marginal association with frequency of contact. Isaacs (1988) found that setting up and maintaining a schedule of regular visitation was positively associated with the parents' ability to establish a nonhostile relationship. Moreover, results of Wallerstein and Kelly's study (Kelly, 1981) indicate that feelings of anger toward their former spouses hindered effective involvement on the part of fathers; angry custodial mothers would sometimes sabotage fathers' efforts to visit their children, and embittered fathers would often not visit their children as a means to avoid contact with their former wives.

Similarly, analysis of the first wave of Ahrons's Binuclear Families study provided additional evidence that the coparental relationship has an important influence on a father's involvement with his children (Ahrons, 1983). Specifically, Ahrons found that the quality of the relationship between 98 pairs of former spouses was associated with the amount of involvement that fathers had with their children one year following the divorce.

Although empirical research suggests that the quality of the relationship between former spouses has an important influence on father involvement, the bulk of that evidence is based on the interaction of couples shortly after the divorce decree. There is little known about how the relationship between former spouses changes and about how such changes affect the father's contact and involvement with his children over the years following the divorce. Does the effect of their relationship remain constant over time, or is it most pronounced immediately following the divorce?

The research and clinical literature agree that the time of greatest stress and disequilibrium occurs within the first two years after separation; then it appears that the postdivorce binuclear family begins to reorganize and stabilize (Ahrons, 1980; Ahrons \& Rodgers, 1987). It would then follow that the patterns of paternal involvement and the dynamics of the relationship between the former spouses would also become increasingly stabilized over time. While the relationship between the mother and father during the first year after the divorce appears to affect father-child involvement, its importance is likely to decline in subsequent years as the patterns of the new family organization become established. Based on this theoretical formulation, the main hypothesis of the present series of analyses is that the impact of the relationship with the former spouse on the father's contact with his children will diminish over the years following divorce. A second hypothesis is that the relationship between former spouses will have a greater impact on paternal involvement in parenting responsibilities than on actual father-child contact.

\section{METHOD}

The data used in this paper come from the Binuclear Family Research Project. The sample for this longitudinal study was drawn in 1979 from the public divorce-court records in Dane County, Wisconsin (Ahrons, 1981, 1983; Bowman \& Ahrons, 1985). In order to be included in the study, couples had to meet four criteria: 1) The couple could not have reconciled. 2) Both former spouses had to be current residents of Dane County. 3) Both former spouses had to agree to be part of the study. 4) The noncustodial parent had to have seen the children within the past two months. 
Ninety-eight couples (196 individuals) participated in the first wave of the study; 54 were cases of maternal custody, 28 were joint custody, and 16 were either split custody (with some children living with the father and some with the mother) or paternal custody. Two years later (three years following their divorce), 176 of the original 196 divorced parents $(90 \%)$ participated in the second wave of the study (Time 2). This represented 80 couples, as well as one member from 16 additional couples. After another two years (Time 3, five years postdivorce), a total of 178 parents participated, including several who were not interviewed at Time 2 . This $90 \%$ response rate is unusually high for longitudinal studies, with a loss of only two families from the original sample who were unavailable for any follow-up over the five years.

Data for all three waves were gathered using semi-structured interviews that lasted from one and one-half to two and one-half hours. Items that comprise the major variables in the study were worded exactly the same in all three interview schedules to ensure accurate comparability over time.

The sample is predominantly white and middle class. The majority of respondents were in their mid-thirties at Time 1 , with an age range of 19 to 64 . The length of marriage ranged from one to 25 years, the average being ten years. The families averaged two children, with a range from one to five. At Time 1, $20 \%$ of the children were preschool age, $50 \%$ were elementaryschool age, and $30 \%$ were adolescents; they ranged in age from two to 16 . About $75 \%$ of the women were employed full-time. A little over half of the fathers and $38 \%$ of the mothers were college graduates. By Time $3,45 \%$ of the mothers in the longitudinal sample had remarried, compared to $72 \%$ of the fathers. At the beginning of the study, all of the former spouses lived in the same county; at Time 3,11\% of them lived more than 300 miles from each other.

Because the focus of this analysis is on the involvement of noncustodial fathers, cases of split or paternal custody were excluded. A decision had to be made about whether or not to include joint-custody cases. Even though fathers who have joint custody have shared legal custody, there are still wide variations in father-child contact and involvement. Moreover, comparisons between maternal custody and joint-custody cases revealed similar demographic characteristics and similar levels of conflict around divorce issues (Bowman \& Ahrons, 1985). Therefore, the joint-custody cases were included in this analysis. The exclusion of split and paternal-custody cases reduced the eligible sample size to 82 couples. In addition, the lack of response by either parent in 18 of the cases at Time 2 or Time 3 further reduced the size of the sample. In all, 64 couples participated in all three waves and were included in the present analyses.

During the course of the study, nine families in the longitudinal sample changed their custody disposition. Six cases of maternal custody at Time 1 changed during the twoyear interval prior to Time 2, two to paternal custody and four to split custody. Between Time 2 and Time 3, two cases of maternal custody changed disposition, one to split and the other to joint custody. During that same time, a joint-custody case switched to paternal custody. Unfortunately, the interviews provide no explanation of why the families changed. However, these nine families are not discernibly different from the other longitudinal cases in demographic characteristics or in father contact and involvement at Time 1.

\section{Measurement}

Paternal involvement is a global concept that can mean many things. In Ahrons's Binuclear Families study, this concept was measured in two ways (Ahrons, 1981). The first was the measurement of the amount of actual contact between the fathers and their children. However, the measurement of the amount of father-child contact does not adequately describe a father's involvement with his children. Some fathers have little involve- 
ment in the actual parenting of the children, while others remain deeply involved in the responsibilities of child rearing. The second way to conceptualize father-child interaction tried to capture this dimension; it measured the fathers' involvement in parental activities, such as disciplining the children and attending school functions.

Dependent variables. Paternal involvement was assessed by using two measures, the Father-Child Contact Scale and the Parental Involvement Scale. These variables are measured from both the male's and the female's perspective. Consequently, we have data on the father's self-report of his interaction with his children, as well as the mother's perception of the father's involvement. These variables are the same ones used in analyses of the first wave of data (Ahrons, 1981, 1983; Bowman \& Ahrons, 1985). The contact variable assessed both frequency of fathers' contact with their children and duration of the visits. The ordinal variable has ten levels of amount of interaction, ranging from three days and nights a week to less than yearly contact.* Summer visitation was also considered in the coding. The variable was coded from responses to open-ended questions about visitation patterns between the noncustodial parent and the children.

The Parental Involvement Scale is a fivepoint Likert-type scale that measures involvement in eight parental activities, including disciplining, celebrating holidays, discussing children's problems, and attending church and school activities. The reliability coefficients of the scale for the men's perception, using Cronbach's Alpha, at Time 1 , Time 2, and Time 3 were .92, .93, and .95 , respectively. The comparable coefficients from the women's perspective were $.92, .95$, and .95 .

Independent variables. The quality of the relationship with the former spouse was assessed by the Quality of Coparental Communication scale, which consists of ten items that tap conflict, such as arguing when discussing the children, having differences of opinion about child rearing, and having an underlying atmosphere of hostility and tension. The scale also includes items about supporting the other parent in his or her parenting role, such as accommodating changes in visiting arrangements. Separate scales were developed for men and women, with the women's scales having a reliability coefficient of $.87, .87$, and .86 at Time 1 , Time 2 , and Time 3 , respectively. The same coefficients for the men were $.86, .85$, and .86 .

Several control variables were included in the analyses. Age of youngest child was included to control for the stage in the family life-cycle, and educational level of the parents was included to control for family socioeconomic status. In addition, the remarriage of either parent, the geographical distance between fathers and their children, and the presence of boys in the family were included in some of the analyses as control variables.

\section{Analytic Design}

Before the main hypothesis was tested, means and standard deviations of the dependent variables were determined to provide a context for the rest of the results. The two main hypotheses were tested using path analysis. Path analysis, when applied to panel data, uses a series of basic regression models to measure stability and change in dependent variables over time, as well as to identify independent variables that influence changes in the dependent variable (Johnson, 1988). The general technique is to regress the Time-2 dependent variable

\footnotetext{
*The categories for the father-child contact variable, including descriptions, are as follows: $10=$ three days and nights per week, plus summers. $9=$ two days and nights per week, plus summers. $8=$ once a week overnight or twice a month for several nights. $7=$ twice a month overnight. $6=$ at least weekly contact; no regular overnights. $5=$ monthly contact; overnight or several nights. $4=$ less than weekly contact; at least monthly; no regular overnights. $3=$ less than monthly contact; overnight or over several nights, part of summer. $2=$ less than monthly contact; at least yearly; no overnight. $1=$ less than yearly.
} 
on the Time-1 dependent variable. The path coefficient of the Time-1 variable indicates the degree of stability in the variable between Time 1 and Time 2.

Independent variables are also included in the regression equation. Their path coefficients indicate the influence of these variables on the Time- 2 dependent variable when controlling for the Time- 1 dependent variable. This is interpreted as indicating their influence on change in the dependent variable between Time 1 and Time 2 .

The scores of the mother's and the father's perceptions of paternal contact and involvement were combined to form a couples score. This was done by averaging the two scores. In a few cases, although a person participated in all three waves of the study, data were missing on one of the dependent variables for one of the waves. In these cases, the score of the remaining member of the couple was used to represent the score of the couple for that particular variable. This was done to minimize the reduction in the number of cases in the analyses due to missing data. During the analyses, the path models were analyzed using this strategy of dealing with missing data and compared to identical models that did not compensate for missing data. A comparison showed that the path coefficients in the two models were not different.

Using the couples score as the dependent variable, path models were analyzed separately for men and women. That is, the effect of men's and women's perception of the quality of the relationship on paternal involvement and contact was examined in separate path models. This analytic design resulted in four path models: 1) the effect of women's perception of the quality of the relationship on paternal involvement; 2) men's perception of the quality of the relationship on their involvement; 3) women's perception of the quality of the relationship on father-child contact; and 4) men's perception of the quality of the relationship on father-child contact.

\section{Attrition Analysis}

Preliminary analysis was performed to test for bias due to sample attrition during the three waves of data collection. Based on $t$-tests comparing respondents who participated at all three time periods with those who participated only at Time 1 or only at Time 1 and Time 2, there were no significant differences in paternal contact, involvement, or quality of the relationship. Education of the fathers approached significance, with longitudinal respondents tending to be more educated.

\section{RESULTS \\ Descriptive Statistics}

The fathers in the study maintained fairly moderate contact and involvement with their children through five years following divorce. The mean level of father-child contact was 7.56 at Time $1(S D=2.04), 7.40$ at Time $2(S D=2.57)$, and 7.32 at Time 3 $(S D=2.66)$. This indicates that, on average, children stayed the night with their fathers two or three times a month.

The mean score of paternal involvement was 3.38 at Time $1(S D=.95), 3.25$ at Time $2(S D=.93)$, and 3.21 at Time $3(S D=$ $1.10)$. With a range in the Father Involvement Scale of 1 ("not at all") to 5 ("very much"), the mean scores indicate that these fathers were generally "somewhat" involved in the parenting of their children.

\section{Paternal Involvement}

Women's perspective. The hypothesis that the quality of the relationship with the former spouse would have a significant, yet declining, influence on father involvement was supported. Based on the path model analysis, ${ }^{*}$ the women's perception of the relationship, with the couples score of father

*Figures delineating the path model and correlations for women's perception of paternal involvement, men's perception of paternal involvement, women's perception of father-child contact, and men's perception of father-child contact are available from the second author. 
involvement as the dependent variable, had a significant impact on paternal involvement at Time 1 (path coefficient $=.53$, $p<.01$ ). This effect is independent of the significant effects of the women's education ( path coefficient $=.24, p<.05$ ) and the age of the youngest child ( path coefficient $=$ $-.30, p<.01$ ).

The quality of the relationship had a decreasing impact on change in fathers' involvement between Time 1 and Time 3. At Time 2, the effect was still significant (path coefficient $=.16, p<.05$ ), but it was only one-third as strong as it was at Time 1 . By Time 3, the impact had decreased to virtually zero (path coefficient $=-.03, \mathrm{NS}$ ).

While the influence of the relationship with the former spouse on father involvement decreased over time, the pattern of paternal involvement became more stabilized. The coefficient for the path between paternal involvement at Time 1 and Time 2 was $.79(p<.01)$, indicating a high level of stability. Between Time 2 and Time 3, the pattern of fathers' involvement was even more stable, with a path coefficient of .84 $(p<.01)$.

As hypothesized, part of the reason for the decreasing influence of the relationship with the former spouse on paternal involvement was that the pattern of this involvement was very stable after Time 1 . Because the path model measured the influence of quality of the relationship at Time 2 and Time 3 on change in paternal involvement, the lack of significance of the relationship variable was largely due to the lack of change in the fathers' involvement.

Men's perspective. The same pattern of paths emerged in the path model that applied to the men's perception of the quality of the relationship. Their perception of the relationship at Time 1 had a significant influence (path coefficient $=.32, p<.05$ ) on paternal involvement at that stage. The control variables also had an impact on paternal involvement at Time 1, although the effects only approached significance.

The impact of the quality of the relation- ship on fathers' involvement diminished after Time 1. Although the relationship was significant at Time 1 , it failed to approach significance at Time 2 or Time 3 (path coefficient $=.10$ and -.10 , respectively) . Similar to the women's model, paternal involvement was very stable between Time 1 and Time 2 (path coefficient $=.80, p<.01$ ), as well as between Time 2 and Time 3 (path coefficient $=.83, p<.01$ ), according to fathers' perceptions.

\section{Father-Child Contact}

Women's perspective. The hypothesis that the impact of the quality of the relationship with the former spouse on father-child contact would decline over time was supported in the women's model. The relationship had a significant effect on father-child contact at Time 1 (path coefficient $=.33, p<.01$ ). However, it had virtually no impact on change in contact after Time 1 . This was true even though there was only moderate stability in contact between Time 1 and Time 2. After Time 2, the patterns of contact became very stabilized, and the quality of the relationship at Time 3 had no effect on change in contact between Time 2 and Time 3.

Men's perspective. Contrary to the women's model, the men's perception of the quality of the relationship did not have a significant effect on father-child contact at Time 1 (path coefficient $=.12$, NS). The effects of the relationship on change in contact between Time 1 and Time 2, as well as between Time 2 and Time 3, were virtually zero (path coefficients of .01 and -.04 , respectively). Although this represents a slight decrease in the effect of the quality of the relationship on paternal contact over time, the failure of the variable to be significant at Time 1 leaves the main hypothesis only partially supported.

\section{Paternal Involvement vs. Father Contact}

The second hypothesis, that the impact of the quality of the relationship would be greater for paternal involvement than for 
father-child contact, was supported. From the women's perspective, the effect of quality of the relationship on the Time-1 dependent variable, as measured in path coefficients, was .53 for paternal involvement, compared to .33 for father-child contact $(p<.01)$. Moreover, the impact of the relationship at Time 2 was significant for paternal involvement (path coefficient $=.16$, $p<.05$ ), but did not reach significance for father-child contact. By Time 3, the effect of the relationship was virtually zero in both models.

The hypothesis was also supported in the men's path models. While the effect of the relationship at Time 1 was significant for paternal involvement (path coefficient $=$ $.32, p<.05$ ), it was not significant for father-child contact (path coefficient $=.12$, NS). Although the paths at Time 2 and Time 3 were also greater for paternal involvement than for paternal contact, they were not significant in either model.

\section{Analyses Using Control Variables}

Additional analyses were performed to determine if remarriage of either spouse affected the results of the study. This was done by analyzing separate path models for those who remarried within five years of the divorce and those who had not remarried. A comparison of the corresponding paths in the models indicated that the paths were not significantly different. That is, the results of the models were essentially the same, indicating that the remarriage of either spouse did not affect the results of two major hypotheses of the study.

The effects of having boys in the family and of the geographical distance between fathers and children were also examined by comparing the results of path models that controlled for these variables. Results indicated that path models containing families that had boys and models where there were no boys in the families were essentially the same. Similarly, the geographical distance between fathers and children had no effect on the correlation between the relationship with the former spouse and paternal contact and involvement throughout the five years following divorce. Models were examined that compared those fathers who had moved more than $\mathbf{5 0}$ miles away from their children and those who remained closer than 50 miles; no differences were found in the path coefficients.

\section{DISCUSSION}

The findings generally support the hypothesis that the impact on paternal involvement of the quality of the divorced spouses' relationship would be significant but would decline after the first year following divorce. The age and gender of the youngest child, remarriage, father's education, and geographical proximity did not have an effect on the father's involvement. The level of conflict and support between the former spouses had an importance influence on the reorganizing process of these families. High levels of conflict and little cooperation tended to hinder father-child contact and, especially, father's involvement, while low conflict and high support facilitated the continued father involvement in the children's lives.

Consistent with Ahrons's $(1979,1980)$ systemic stages of divorce, the binuclear family systems had generally reorganized by the end of the first year following the divorce. The patterns of relationships within the restructured family had taken form and become stabilized. Although our first interview occurred one year after the legal divorce (usually 18-24 months after physical separation), other studies that used separation as the point of initial measurement or that controlled for time since separation obtained similar results (Hetherington, Cox, \& Cox, 1978; Isaacs, 1988). Therefore, it is generally agreed upon now, based on both empirical and clinical evidence, that it takes about 18 months to two years for the family system to stabilize.

Because we chose to use the court records to obtain our sample, rather than a referred or clinical sample, the legal divorce was the 
most reliable entry point. Interestingly, we found considerable discrepancies between husbands and wives in noting when they actually separated; this influenced our decision not to control for time since separation. Such things as brief "reunions" after a separation, separating but remaining in the same dwelling, extended business travel or other unofficial separations that then turned into "official" separations, and trial separations that one but not the other spouse counted as a separation all confuse actually pinpointing the separation date.

In drawing conclusions based on this study, it is important to take into account that the criteria we used to select our sample may have resulted in a bias in the direction of the better-functioning binuclear families. The requirements - that both parents participate, that both reside within the same county at Time 1 , and that the nonresidential parent and child had at least one contact during the two months prior to our sampling-may have excluded those parents who were the most hostile and the least likely to "coparent." In the present study the fathers tended to remain more involved in the lives of their children than has been the case in most other studies. As reported by the fathers, more than $75 \%$ visited their children at least twice a month five years after the divorce. Most studies have reported that between half and two-thirds of fathers see their children about twice a month. This is the most typical pattern for noncustodial fathers in maternal-custody families (Kelly, 1981).

One methodological issue is important to note with respect to differences in father contact and involvement reported by different studies. How involved fathers are often depends on whom you ask. In general, fathers tend to perceive themselves as having more consistent contact and more involvement than mothers perceive them to have. Most studies have not interviewed both parents, but, in the few studies that have, a gender difference has emerged. Not only have we found this to hold true in the United
States, but also, in a cross-national study of nine countries, similar gender discrepancies were in evidence (Ahrons \& Sorensen, 1985). It may be, for example, that Furstenberg and colleagues (Furstenberg, Morgan, \& Allison, 1987; Furstenberg \& Nord, 1985; Furstenberg, Nord, Peterson, \& Zill, 1983) would have found higher levels of contact if they had sampled fathers instead of mothers. Another methodological issue that should be given greater attention, since it is likely to produce divergent findings, is the actual year of the divorce. The social context of divorce has been changing rapidly in our society, and a 1960 s divorce is likely to be very different in some important ways from a 1980s divorce. For example, the increase in the divorce rates has reduced much of the stigma attached to divorce for both parents and children, and the recent men's movement has put greater emphasis on the father's role. Add to this the sampling and measurement differences, and it becomes difficult to draw conclusions with any degree of certainty. In her review of the literature on the long-term effects of divorce on children, Wallerstein (1991) noted that "these studies reflect a complexity that was unanticipated when the work of divorce research began" ( $p .359)$.

Even given these several shortcomings in the existing research, the present findings are important to clinicians in their increasing practice with divorced families. The growing stability of contact and involvement among fathers in this study from the first to the fifth year following divorce points to the importance of early clinical intervention. These data, along with findings of other studies (Hetherington, Cox, \& Cox, 1978; Isaacs, 1988; Wallerstein \& Kelly, 1980), provide evidence that it is during the first year that divorcing families reorganize their family system and establish patterns of interaction that remain fairly stable thereafter.

\section{CONCLUSIONS}

The importance of the year immediately following the divorce in setting a tone for 
the coparental relationship suggests that attention be focused on intervention during this crucial time to resolve conflicts between the former spouses. The extent to which this is achieved may strongly influence the establishment of stable patterns of father-child involvement. The results of the present analyses also suggest that the relationship between the former spouses has a greater impact on the parental responsibilities of the fathers than on the amount of contact that they have with their children. It also appears that the relationship between former spouses is a significant predictor of compliance in economic support (Wright \& Price, 1986) and that there is an association between the level of paternal contact and fathers' provision of financial support (Seltzer, Schaeffer, \& Charng, 1989).

These results also suggest that the women's perception of the quality of the relationship has a greater impact than the men's perception on the level of father involvement and contact. At least in divorced families in which the mother has primary physical custody, the implication is that mothers are the "gatekeepers" of the children; they are able at least partially to control and regulate father-child involvement and contact. When possible, intervention strategies need to include all members of the family system. In marital therapy, we often help couples understand the other spouse's perspective; in divorce therapy, we need to pursue the same path. By acknowledging the normalcy of different perceptions by gender and by custodial status, we can assist parents in understanding the position of the other parent and attempt to narrow the perceptual gap that often creates and perpetuates the conflicts.

Early intervention strategies can also teach divorced parents problem-solving techniques that they may utilize in future disagreements over the years. Explaining to parents that they will need to continue to have a relationship that will affect their children's future emotional adjustment provides a reality that divorcing parents often deny. Encouraging them to think of themselves as a binuclear family in which they must continue to serve the same function for their children as they did in their prior nuclear family helps them understand the complexities of their newly restructured family (Ahrons, in press).

Although based on a small subsample of 64 divorced couples, the findings of this longitudinal study have helped to clarify the influence of the relationship between former spouses on father involvement and contact during the five years following divorce. Additional studies using different samples are needed to replicate these findings, provide greater generalizability, and further increase our understanding of relationships in binuclear families.

\section{REFERENCES}

Ahlburg, D.A., \& De Vita, C.J. (1992). New realities of the American family. Population Bulletin, 47, 2-43.

Ahrons, C. (1979). The binuclear family: Two households, one family. Alternative Lifestyles, 2, 499515.

Ahrons, C. (1980). Divorce: A crisis of family transition and change. Family Relations, 29, 533-540.

Ahrons, C. (1981). The continuing coparental relationship between divorced spouses. American Journal of Orthopsychiatry, 51, 415-428.

Ahrons, C. (1983). Predictors of paternal involvement postdivorce: Mothers' and fathers' perceptions. Journal of Divorce, 6, 55-69.

Ahrons, C. (in press). The good divorce. New York: HarperCollins.

Ahrons, C., \& Rodgers, R. (1987). Divorced families: A multidisciplinary developmental view. New York: Norton.

Ahrons, C., \& Sorensen, A. (1985). Father-child involvement. In J. Trost, C. Szombarthy, \& I. Weeds (Eds.), The aftermath of divorce: Coping with change (pp. 171-198). Budapest, Hungary: Akademiai Kiado.

Bowman, M., \& Ahrons, C. (1985). Impact of legal custody status on fathers' parenting postdivorce. Journal of Marriage and the Family, 47, 481-488.

Furstenberg, F., Morgan, P., \& Allison, S. (1987). Paternal participation and children's well-being after marital dissolution. American Sociological Review, 52, 695-701.

Furstenberg, F., \& Nord, C. (1985). Parenting apart: Patterns of childrearing after marital disruption. Journal of Marriage and the Family, 47, 893-904.

Furstenberg, F., Nord, C., Peterson, J., \& Zill, N. (1983). The life course of children of divorce: Marital disruption and parental contact. American Sociological Review, 48, 656-668. 
Glick, P. (1990). American families: As they are and were. Social Science Review, 74, 139-144.

Guidubaldi, J., Cleminshaw, H.K., Perry, J.D., \& McLoughlin, C.S. (1983). The impact of parental divorce on children: Report of the nationwide NASP study. School Psychology Review, 12, 300-323.

Guidubaldi, J., \& Perry, J. (1984). Divorce, socioeconomic status, and children's cognitive-social competence at school entry. American Journal of Orthopsychiatry, 54, 459-468.

Guidubaldi, J., \& Perry, J. (1985). Divorce and mental health sequelae for children: $A$ two year follow-up of a nationwide sample. Journal of the American Academy of Child Psychiatry, 24, 531-537.

Hess, R., \& Camara, K. (1979). Postdivorce family relationships as mediating factors in the consequences of divorce for children. Journal of Social Issues, 35, 79-96.

Hetherington, E., \& Camara, K. (1984). Families in transition: The process of dissolution and reconstruction. In R.D. Park (Ed.), Review of child development: The family, 7 (pp. 398-439). Chicago: University of Chicago Press.

Hetherington, E., Cox, M., \& Cox, R. (1978). The aftermath of divorce. In J.H. Stevens, Jr. \& $\mathbf{M}$. Mathews (Eds.), Mother/child, father/child relationships (pp. 149-176). Washington, DC: The National Association for the Education of Young Children.

Hetherington, E., Cox, M., \& Cox, R. (1982). Effects of divorce on parents and children. In M.E. Lamb (Ed.), Nontraditional families: Parenting and child development (pp. 233-288). Hillsdale, NJ: Lawrence Erlbaum.

Hetherington, E., Cox, M., \& Cox, R. (1985). Longterm effects of divorce and remarriage on the adjustment of children. Journal of the American Academy of Child Psychiatry, 24, 518-530.

Hetherington, M., Stanley-Hagan, M., \& Anderson, E. (1989). Marital transitions: A child's perspective. American Psychologist, 44, 303-312.

Isaacs, M. (1988). The visitation schedule and child adjustment: A three-year study. Family Process, 27, 251-256.

Jacobson, D. (1978). The impact of marital separation/ divorce on children: II. Interparent hostility and child adjustment. Journal of Divorce, 2, 3-19.
Johnson, D. (1988). Panel analysis in family studies. Journal of Marriage and the Family, 50, 949-955.

Kelly, J. (1981). The visiting relationship after divorce: Research findings and clinical implications. In I.R. Stuart \& L.D. Abt (Eds.), Children of separation and divorce: Management and treatment (pp. 338-361). New York: Van Nostrand Reinhold.

Kelly, J. (1993). Current research on children's postdivorce adjustment. Family and Conciliation Courts Review, 31, 29-49.

Koch, M., \& Lowery, C. (1985). Visitation and the noncustodial father. Journal of Divorce, 8, 47-65.

Peterson, J., \& Zill, N. (1986). Marital disruption, parent-child relationships, and behavior problems in children. Journal of Marriage and the Family, 48, 295-307.

Seltzer, J., Schaeffer, N., \& Charng, H. (1989). Family ties after divorce: The relationship between visiting and paying child support. Journal of Marriage and the Family, 51, 1013-1032.

Tepp, A. (1983). Divorced fathers: Predictors of continued paternal involvement. American Journal of Psychiatry, 140, 1465-1469.

Tschann, J., Johnston, J., Kline, M., \& Wallerstein, J. (1989). Family process and children's functioning during divorce. Journal of Marriage and the Family, 51, 431-444.

Wallerstein, J. (1985). Children of divorce: Report of a ten-year follow-up of older children and adolescents. Journal of the American Academy of Child Psychiatry, 24, 545-553.

Wallerstein, J. (1991). The long-term effects of divorce on children: A review. Journal of the American Academy of Child and Adolescent Psychiatry, 30, 349-360.

Wallerstein, J., \& Kelly, J. (1980). Surviving the breakup. New York: Basic Books.

Wright, D., \& Price, S. (1986). Court-ordered child support payment: The effect of the former spouse relationship on compliance. Journal of Marriage and the Family, 48, 869-874.

Zill, N. (1983). Happy, healthy, and insecure. New York: Doubleday. 


\section{Erratum}

In the article "The Effect of the Postdivorce Relationship on Paternal Involvement: A Longitudinal Analysis," by Constance R. Ahrons and Richard B. Miller, published in the last issue of this Journal (July 1993, 63(3), 441-450), the following acknowledgement was inadvertently omitted from the title-page footnote:

The research reported was supported by NIMH Grant No. 34397 to Constance R. Ahrons, principal investigator. 